\title{
A Decade of Fighting Invasive Meningococcal Disease: A Narrative Review of Clinical and Real-World Experience with the MenACWY-CRM Conjugate Vaccine
}

Yara Ruiz Garcia • Véronique Abitbol • Michele Pellegrini •

Rafik Bekkat-Berkani · Lamine Soumahoro

Published online: September 30, 2021

(C) The Author(s) 2021, corrected publication 2022

\section{ABSTRACT}

The quadrivalent $\mathrm{A}, \mathrm{C}, \mathrm{W}$ and $\mathrm{Y}$ meningococcal vaccine conjugated to nontoxic mutant of diphtheria toxin (MenACWY-CRM) has been licensed since 2010 for the prevention of invasive meningococcal disease (IMD), an uncommon but life-threatening condition. Here, we summarize the experience accrued with MenACWY-CRM during the first decade since its licensure, by providing an overview of clinical trials investigating the safety, immunogenicity and co-administration of MenACWYCRM with other vaccines as well as presenting real-world evidence regarding the impact of MenACWY-CRM vaccination on carriage and

Supplementary Information The online version contains supplementary material available at https:// doi.org/10.1007/s40121-021-00519-2.

Y. Ruiz Garcia · R. Bekkat-Berkani

Global Medical Affairs, GSK, Rockville, MD, USA

V. Abitbol

Global Medical Affairs, GSK, Rueil-Malmaison, France

M. Pellegrini

Global Clinical Research and Development, GSK, Siena, Italy

L. Soumahoro $(\bowtie)$

Global Medical Affairs, GSK, GSK Vaccines, Avenue

Fleming 20, 1300 Wavre, Belgium

e-mail: lamine.m.soumahoro@gsk.com
IMD incidence. MenACWY-CRM has demonstrated an acceptable clinical safety profile across a wide range of age groups; no safety concerns have been reported in special populations, such as immunocompromised infants and toddlers, or pregnant women. MenACWYCRM has also been proven to be immunogenic in various age groups and geographic settings, and a booster dose has been shown to elicit strong anamnestic responses in all studied populations, irrespective of the vaccine used for priming. With no clinically relevant vaccine interactions reported, MenACWY-CRM is being conveniently integrated into existing vaccination programs for various age and risk groups; this possibility of co-administration helps improving vaccine coverage and streamlining the healthcare process of fighting preventable infectious diseases. Vaccination of adolescents and adults has been proven to reduce nasopharyngeal carriage for serogroups $\mathrm{C}, \mathrm{W}$ and $\mathrm{Y}$, which is an important element in reducing transmission. Real-world evidence indicates that MenACWY-CRM can reduce IMD incidence even in high-exposure groups. When combined with vaccines against serogroup B meningococci, MenACWY-CRM can offer protection against five of the most common serogroups responsible for IMD, which is an important advantage in the continuously evolving landscape of meningococcal serogroup epidemiology. 


\section{PLAIN LANGUAGE SUMMARY}

Invasive meningococcal disease is an uncommon but life-threatening infection that appears as meningitis and/or sepsis. It is caused by Neisseria meningitidis, a bacteria commonly present in the throat or nose. Vaccination with MenACWY-CRM (Menveo, GSK) helps to prevent invasive meningococcal disease caused by four of the most common $N$. meningitidis serogroups (A, C, W and Y). This vaccine has been licensed for 10 years: we summarized here all available evidence gathered since the vaccine has been available in general practice, from clinical development to real-world experience. Information gained during clinical trials of MenACWY-CRM confirms that vaccination is well tolerated, has an acceptable safety profile and would induce significant protection when given to individuals of various ages such as infants, toddlers, children, adolescents and adults, and when administered at the same time as routine or traveler vaccinations as well as vaccines against serogroup $B$ meningococci (4CMenB). Vaccination with MenACWY-CRM has been shown to decrease the number of serogroup $\mathrm{C}, \mathrm{W}$ and $\mathrm{Y}$ meningococci found in the nose and throat in adolescents and adults as well as the occurrence of invasive meningococcal disease in a high-exposure population from a real-world setting. MenACWY-CRM can conveniently be integrated into most of the existing vaccination schedules for various age and risk groups. When combined with vaccination against serogroup B meningococci, MenACWY-CRM can contribute to providing protection against five of the most common serogroups responsible for invasive meningococcal disease.

Keywords: Carriage; Co-administration; Immunogenicity; Invasive meningococcal disease; MenACWY-CRM; Menveo; Quadrivalent meningococcal conjugate vaccine; Real-world evidence; Safety; Traveler vaccine

\section{Key Summary Points}

The quadrivalent $\mathrm{A}, \mathrm{C}, \mathrm{W}$ and $\mathrm{Y}$ meningococcal vaccine conjugated to nontoxic mutant of diphtheria toxin (MenACWY-CRM) has been licensed since 2010 for the prevention of invasive meningococcal disease (IMD), an uncommon but life-threatening condition.

Reported evidence indicates that MenACWY-CRM has demonstrated an acceptable safety profile, has been proven as immunogenic in a wide range of age groups and in various geographic settings and can reduce IMD incidence even in high-exposure groups.

Since no clinically relevant interactions were observed between MenACWY-CRM and a broad selection of routine immunizations, traveler vaccines and a vaccine against meningococcal serogroup $\mathrm{B}$ (4CMenB), this vaccine is being conveniently integrated into existing vaccination programs for various age and risk groups.

Even though access to healthcare might be challenging in many countries due to the COVID-19 pandemic, guidance from the World Health Organization recommends countries to prioritize routine immunization of children and urgent catch-up vaccinations.

When co-administered with $4 \mathrm{CMenB}$, a vaccine against serogroup $B$ meningococci, MenACWY-CRM can contribute to providing protection against five of the most common serogroups responsible for IMD, an important advantage in the continuously evolving landscape of meningococcal serogroup epidemiology. 


\section{DIGITAL FEATURES}

This article is published with digital features, including a plain language summary and video, to facilitate understanding of the article. To view digital features for this article go to https:// doi.org/10.6084/m9.figshare.14980980.

\section{INTRODUCTION}

Invasive meningococcal disease (IMD), caused by Neisseria meningitidis, is an uncommon but life-threatening and unpredictable disease that can lead to death in $24 \mathrm{~h}$ [1-3]. Due to the similarity of its early, non-specific symptoms to those of viral illnesses, IMD can easily be misdiagnosed; even with timely and appropriate intervention, the case fatality rate can reach up to $20 \%$ [4] and a high proportion of IMD survivors may experience significant long-term sequelae such as neurological impairment, seizures, limb amputation or hearing loss [3]. Infants, young children, adolescents and/or young adults, immunocompromised patients and those with underlying medical conditions, individuals living in crowded conditions (such as students in college dormitories or military recruits), travelers to endemic or epidemic regions and laboratory personnel working with $N$. meningitidis isolates are considered at an increased risk for developing IMD [5-11].

Based on the capsular polysaccharide structure, N. meningitidis can be classified in 12 serogroups. Worldwide, six of these serogroups, A, $\mathrm{B}, \mathrm{C}, \mathrm{W}, \mathrm{X}$ and $\mathrm{Y}$, are responsible for most IMD cases $[12,13]$. The distribution of the various serogroups fluctuates and varies over time and geographically [13-27] (Fig. 1).

Immunization with polysaccharide-protein conjugated vaccines is an effective means to prevent meningococcal disease caused by serogroups $\mathrm{A}, \mathrm{C}, \mathrm{W}$ and $\mathrm{Y}$, while vaccines based on subcapsular protein antigens can provide protection against serogroup B $[12,28]$. Currently, four quadrivalent meningococcal ACWY conjugate vaccines are licensed in various regions worldwide. These vaccines differ in the protein carrier to which the polysaccharide antigens are conjugated: MenACWY-TT (Nimenrix, Pfizer and the recently licensed MenQuadfi, Sanofi Pasteur) uses tetanus toxoid (TT), MenACWY-DT (Menactra, Sanofi Pasteur) uses diphtheria toxoid (DT), and MenACWY-CRM (Menveo, GSK) uses a nontoxic mutant of diphtheria toxin (CRM197) [29].

To provide a comprehensive overview of the MenACWY-CRM clinical development and realworld experience accrued during the first decade since its licensure, this review summarizes evidence of the vaccine's safety, immunogenicity, co-administration with other vaccines, effect on carriage and real-world impact in a broad range of populations (Fig. 2). This article is based on previously conducted studies and does not contain any new studies with human participants or animals performed by any of the authors.

\section{MENACWY-CRM COMPOSITION, DEVELOPMENT AND LICENSURE}

\section{MenACWY-CRM Composition}

Each dose of MenACWY-CRM contains $10 \mu \mathrm{g}$ of serogroup A meningococcus (MenA) polysaccharide and $5 \mu \mathrm{g}$ of each of serogroup $\mathrm{C}, \mathrm{W}$ and $\mathrm{Y}$ meningococcus (MenC, MenW and MenY) polysaccharides, individually conjugated to Corynebacterium diphtheriae cross-reactive material (CRM197), in an approximate dose of $47 \mu \mathrm{g}$ per vaccine. CRM197 is a mutant form of diphtheria toxin that differs from the wild type by a single amino acid (AA), AA 197 [30-32].

Before administration, the lyophilized MenA component has to be reconstituted using the liquid MenCWY component, contained in $0.5 \mathrm{ml}$ of phosphate-buffered saline [31].

\section{MenACWY-CRM Development}

The development of purified capsular polysaccharide-based vaccines in the 1970s [33] represented a major advance in the fight against IMD at that time. However, the use of polysaccharide vaccines was initially limited to controlling epidemics and outbreaks of IMD, as they did not induce immunological memory, the 


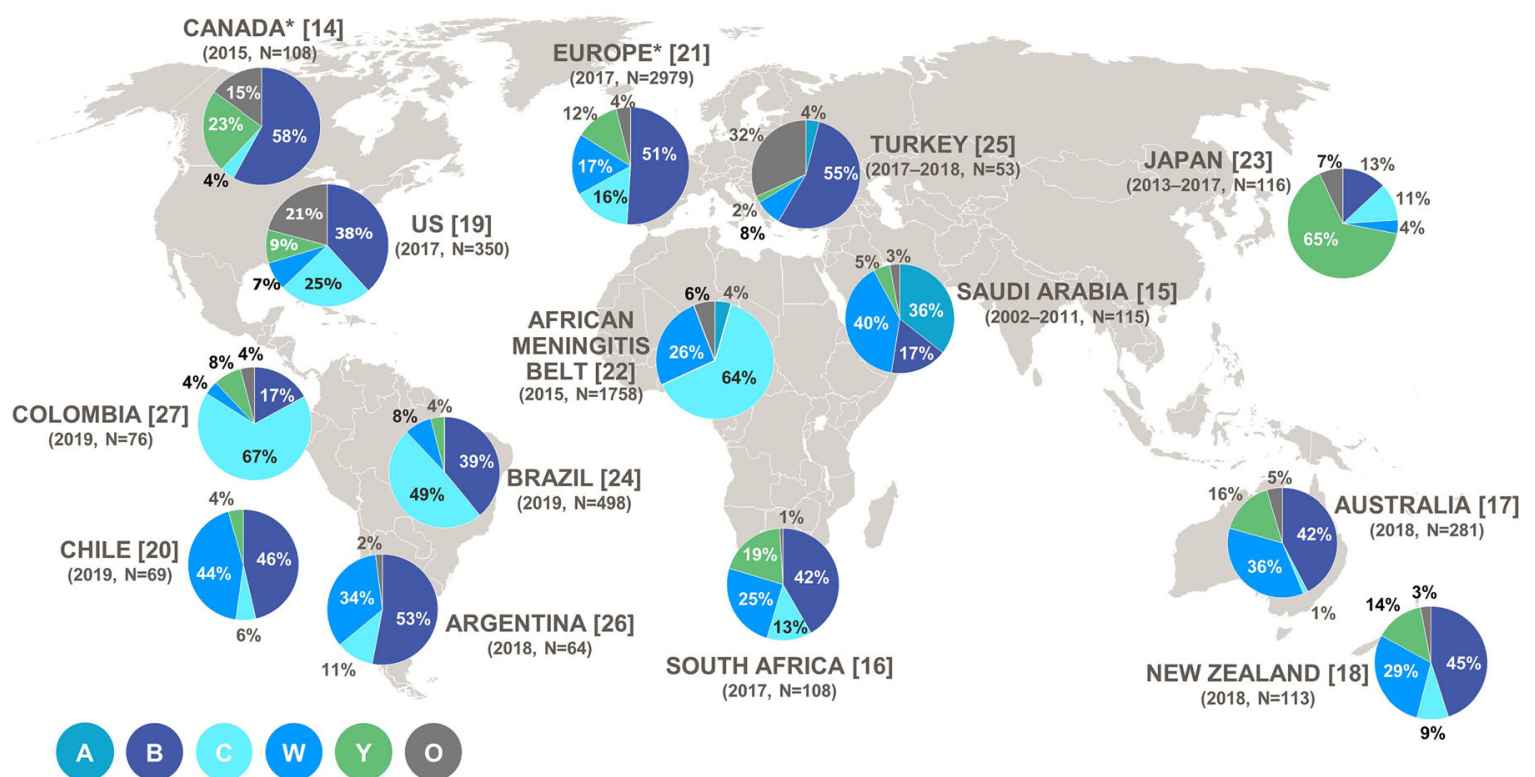

Fig. 1 Global distribution of Neisseria meningitidis serogroups causing IMD. IMD Invasive meningococcal disease, $N$ number of typed isolates across all age groups, $A$ serogroup A meningococcus, $B$ serogroup $\mathrm{B}$ meningococcus, $C$ serogroup $\mathrm{C}$ meningococcus, $W$ serogroup W meningococcus, $Y$ serogroup $\mathrm{Y}$ meningococcus, $O$ other

protection offered was short-lived and, with the exception of MenA, they were poorly immunogenic in infants and young children, and they induced hyporesponsiveness [28, 34-36].

The approach of conjugating the capsular polysaccharide to an immunogenic carrier protein was first used for developing a vaccine against Hemophilus influenzae type $\mathrm{b}[37,38]$ and has been successfully applied to other pathogens as well, including $N$. meningitidis. By inducing a T-cell dependent immune response, polysaccharide-protein conjugate vaccines are highly immunogenic in infants, prime for immunological memory that can be effectively boosted without hyporesponsiveness and interfere with $N$. meningitidis transmission by decreasing carriage $[1,31,34,39]$. The first conjugated meningococcal vaccines were developed against MenC [40]. The UK was the first country to introduce a MenC conjugate vaccine in its national immunization program (NIP) in 1999, leading to a substantial decrease meningococcal serogroups and/or not groupable. ${ }^{*}$ Serogroup A grouped with other meningococcal serogroups. Serogroup distribution cannot directly be compared across countries due to variability in surveillance systems. Percentages may not add up to $100 \%$ because of rounding

of IMD caused by MenC as well as serogroup C nasopharyngeal carriage, in a very short time [41]. To further expand protection against IMD, quadrivalent ACWY conjugate vaccines, including MenACWY-CRM, were subsequently developed.

\section{Initial Licensure of MenACWY-CRM}

MenACWY-CRM was first licensed in 2010 for the active immunization against $N$. meningitidis serogroups $\mathrm{A}, \mathrm{C}, \mathrm{W}$ and $\mathrm{Y}$ of individuals aged between 11 and 55 years in the USA and Canada and of individuals aged 11 years or older at risk of exposure in the European Union (EU) [42]. Similarly to other meningococcal vaccines, evidence of MenACWY-CRM efficacy for licensure was provided based on serologic correlates of protection [35, 43, 44]. Historically, the first correlate of protection was established against MenC by a serum bactericidal assay using human complement (hSBA) and was defined as an hSBA titer $\geq 4$ [5]. Subsequently, this titer 


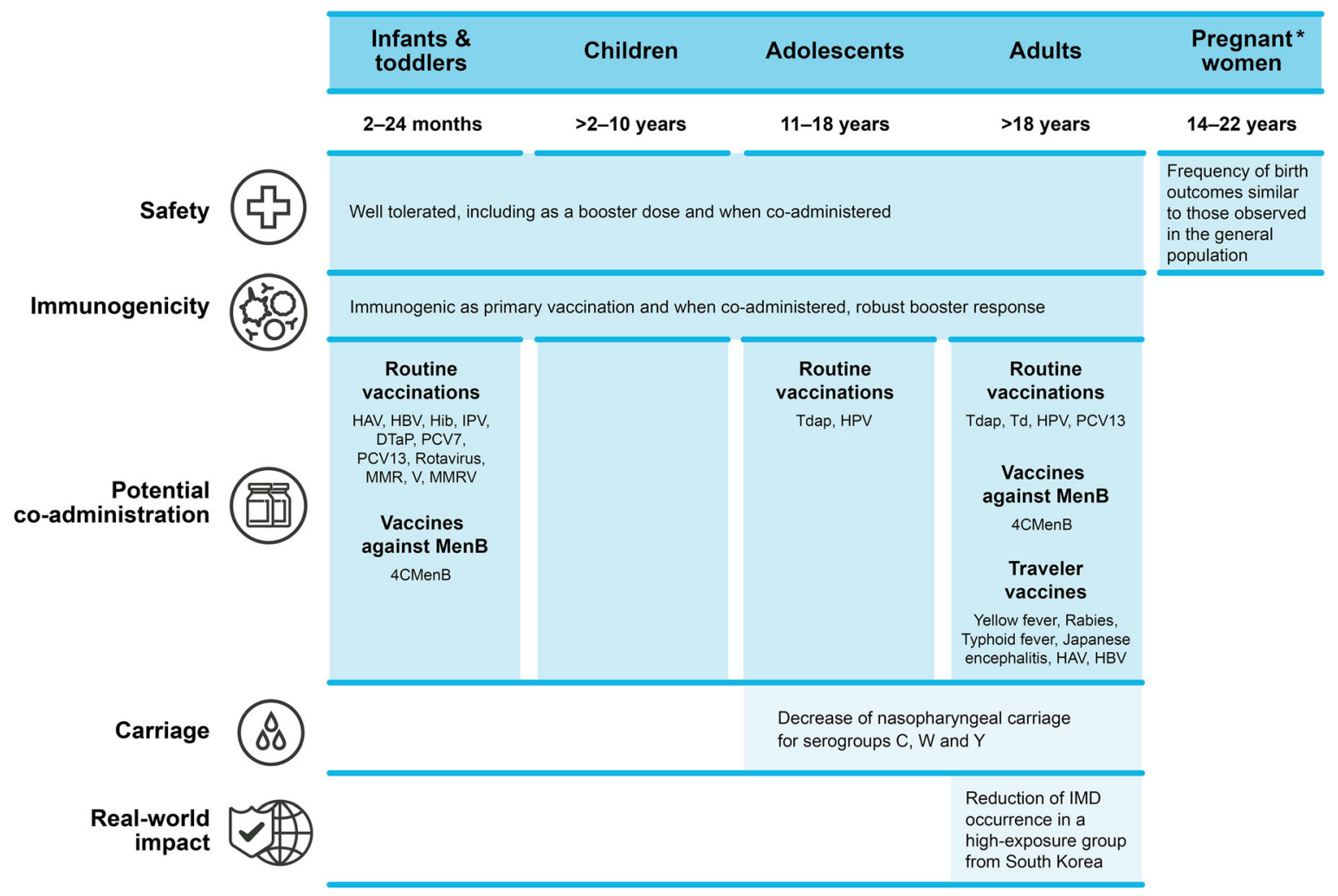

Fig. 2 Summary of the MenACWY-CRM experience accrued during the first decade since its licensure. For more details, see video file 1 in the online/HTML version of the manuscript or follow the digital features link. ${ }^{*}$ MenACWY-CRM inadvertently administered within 28 days prior to conception or during pregnancy. MenACWY-CRM is not indicated in pregnant women. MenACWY-CRM quadrivalent meningococcal vaccine against serogroups $\mathrm{A}, \mathrm{C}, \mathrm{W}$ and $\mathrm{Y}$, conjugated to the nontoxic mutant of diphtheria toxin, $H A V$ hepatitis $\mathrm{A}$ vaccine, $H B V$ hepatitis $\mathrm{B}$ vaccine, Hib Haemophilus influenzae type $\mathrm{b}$ vaccine, IPV inactivated poliomyelitis

was accepted as a correlate of protection against other serogroups $[2,45,46]$. In the clinical development program of MenACWY-CRM, serogroup-specific anticapsular antibody hSBA titers of $\geq 8$ are used as correlates of protection.

\section{Distribution Footprint of MenACWY-CRM}

In the decade since its first approval, MenACWY-CRM has continued its clinical development program and has been licensed in vaccine, $D T a P$ combined diphtheria, tetanus, acellular pertussis, $P C V 7$ 7-valent pneumococcal conjugate vaccine, PCV13 13-valent pneumococcal conjugate vaccine, Rotavirus rotavirus vaccine, $M M R$ measles-mumps-rubella vaccine, $V$ varicella vaccine, $M M R V$ measles-mumpsrubella-varicella vaccine, $T$ dap tetanus-diphtheria-acellular pertussis vaccine, $T d$ tetanus-diphtheria toxoid, $H P V$ human papillomavirus vaccine, MenB Neisseria meningitidis serogroup $\mathrm{B}, 4 C M e n B$ multicomponent vaccine against meningococcal serogroup $\mathrm{B}, \quad I M D$ invasive meningococcal disease

over 60 countries [47], where over 58 million doses have been distributed. Age indications for MenACWY-CRM have also been expanded and currently range from 2 years onwards in the EU, between 2 months and 55 years in the USA and from 2 months onwards in several other countries, such as Argentina, Brazil, Australia and Saudi Arabia. Increasingly more countries have introduced meningococcal vaccination programs over the past years. MenACWY-CRM is the quadrivalent meningococcal vaccine specifically included in the NIP for both infants 
and adolescents in Argentina [48] and for children, adolescents and young adults in Switzerland [49].

\section{SAFETY AND REACTOGENICITY}

Within the last decade, the safety profile of MenACWY-CRM has been assessed in clinical trials and observational studies across all age groups: healthy [50-59] or immunocompromised infants and toddlers [7], children [56, 58-66], adolescents and adults [56, 59, 61-63, 67-72], including pregnant women [73] and elderly individuals up to 75 years of age [61].

Since the initial licensure of MenACWYCRM, two studies assessing the safety of the vaccine across all age groups have been conducted. The first was a post-marketing study involving 3920 individuals aged 2 months to 55 years who received MenACWY-CRM according to local clinical practice in South Korea [56]; the other study analyzed 2614 reports of adverse events (AEs) in MenACWY-CRM recipients between 2010 and 2015, collected from the USA Vaccine Adverse Event Reporting System (VAERS) [59]. In the USA, different post-marketing studies assessed the safety of MenACWYCRM in various age groups, including 138 infants with an indication for meningococcal vaccination, $42 \%$ of whom had impaired immunity (i.e., anatomic/functional asplenia or DiGeorge syndrome) [7], 327 children aged 2-10 years [66], 48,899 adolescents and young adults aged 11-21 years [74] and 92 women who inadvertently received MenACWY-CRM during pregnancy [73]. No major safety concerns were identified in any of the investigated populations and age groups. While a temporal association was observed between the occurrence of Bell's palsy and receipt of MenACWY-CRM in the 11-21 years age group, the risk was significantly higher only for those who received MenACWYCRM concomitantly with other vaccines. In this case, co-administration represents a confounding factor, considering that several of the coadministered vaccines have facial palsy reported as a potential $\mathrm{AE}$ in their labels [74]. These results are also included in a systematic review of post-licensure safety studies conducted in the USA, the conclusions of which further support the favorable safety profile of MenACWY-CRM in a real-world setting [75].

Administration of MenACWY-CRM concomitantly with routine infant vaccines [50-54, 76, 77], tetanus-diphtheria-containing boosters in adolescents and adults [76, 78-80], a quadrivalent human papilloma virus (HPV) vaccine in adolescents [76], traveler vaccines [81-83] and a multicomponent vaccine against meningococcal serogroup B (4CMenB) in infants [84] and high-exposure adults [11, 85] was well tolerated and no safety concerns were identified.

Overall, the most frequent solicited AEs reported after MenACWY-CRM were tenderness and irritability in infants and younger children $[7,50,51,53-56,58,60-63,65]$ and pain, headache and myalgia in older children, adolescents and adults [56, 60-64, 67-70, 72]. These AEs, well known after any vaccine administration, were not severe and generally lasted for one to two days, as reflected in the MenACWYCRM patient leaflet [86].

\section{IMMUNOGENICITY}

Immunogenicity of MenACWY-CRM has been confirmed during the first decade post-licensure across all age groups: infants and toddlers [50-54, 57, 58, 87-89], children [58, 60-65], adolescents and adults [62, 63, 67-69, 72, 90-92], including older adults up to 75 years of age [61]. In addition, a booster dose of MenACWY-CRM induced strong anamnestic responses [58, 64, 65, 68, 69, 72, 91] (Fig. 3). Recently, it has been demonstrated that MenACWY-CRM vaccination elicits protective bactericidal titers against hypervirulent MenC field strains that contributed to IMD outbreaks in Italy [93].

\section{Immunogenicity of Different Dosing Schedules in Infants}

Infants in their first year of life are a high-risk group for IMD. One of the main purposes of developing quadrivalent conjugate vaccines was 


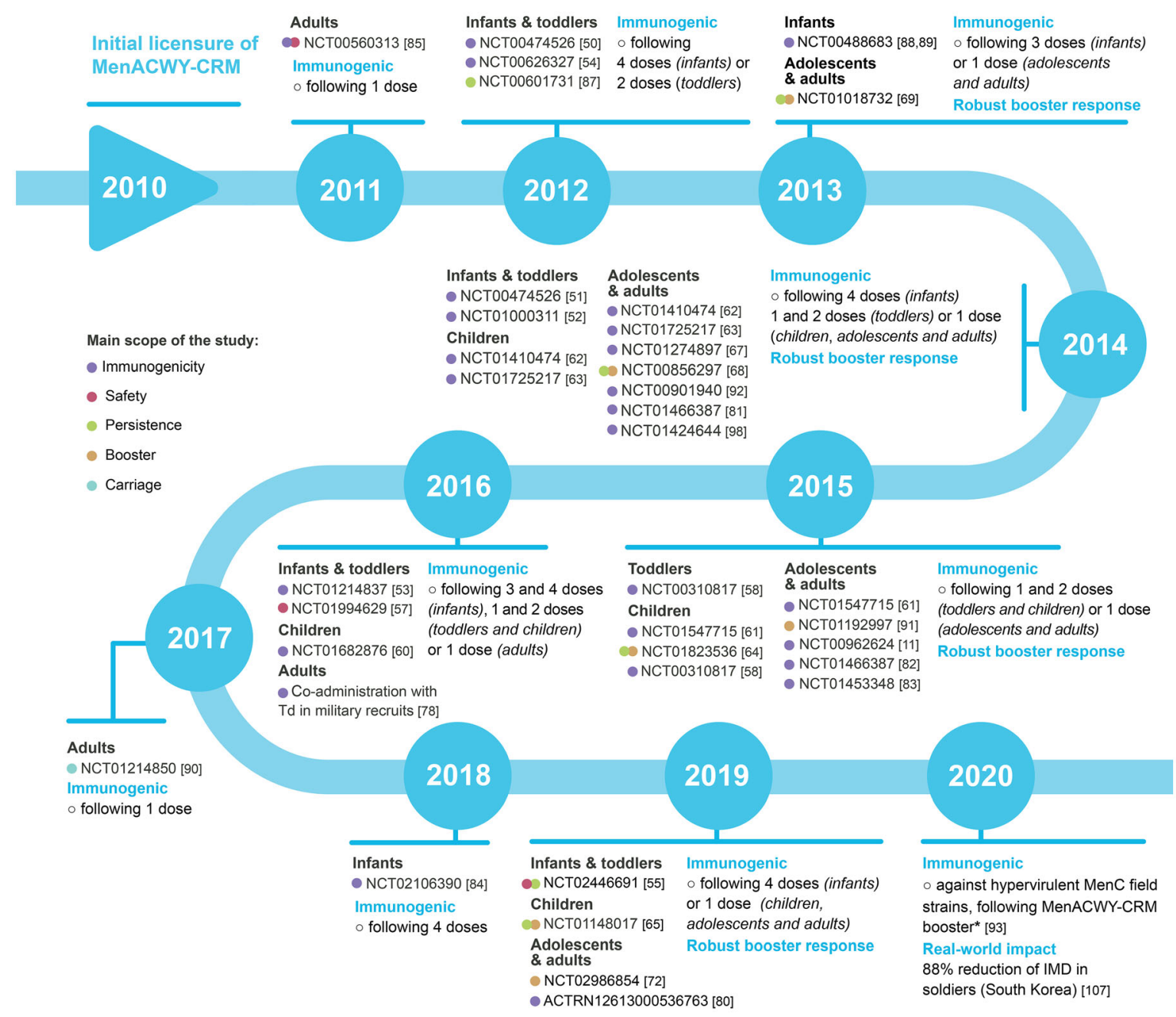

Fig. 3 Available evidence on the immunogenicity of MenACWY-CRM in various populations and age groups and the real-world impact of MenACWY-CRM vaccination, published during the first decade after its licensure. *In children primed with MenACWY-CRM/MenCCRM. MenACWY-CRM quadrivalent meningococcal

to provide protection against IMD as early as possible in this vulnerable population [53].

Immunogenicity of the four-dose infant/toddler MenACWY-CRM schedule has been well established, and immune responses elicited by a three-dose schedule administered at 2, 6 and 12 months [51] or at 2, 4 and 12 months [53] were found to be noninferior to those of a four-dose schedule. In certain settings, depending on the regional epidemiology of IMD, a three-dose vaccination schedule that vaccine against serogroups $\mathrm{A}, \mathrm{C}, \mathrm{W}$ and $\mathrm{Y}$, conjugated to a nontoxic mutant of diphtheria toxin, $T d$ tetanusdiphtheria toxoid, MenC-CRM monovalent meningococcal vaccine against serogroup $C$, conjugated to a nontoxic mutant of diphtheria toxin, IMD invasive meningococcal disease

allows for more flexibility, while potentially reducing the number of vaccination visits, can represent an alternative to the four-dose schedule [53].

\section{Antibody Persistence and Booster Vaccination}

Serogroup-specific bactericidal antibodies induced by vaccination wane gradually over the 
first 5 years post-vaccination; this waning is less marked following vaccination of adolescents ( $>11$ years of age) compared to vaccination in early childhood $[64,69]$. A booster dose of MenACWY-CRM induced robust immune responses with high seroprotection rates, regardless of whether it was administered 6-12 months or 5 years after priming, or whether the children were primed in infancy (with a 3or 4-dose schedule) or in toddlerhood [58, 64, 65, 87].

Teenagers represent another group at increased risk for IMD. To ensure a protective level of antibodies throughout the age groups at higher risk of IMD, a booster dose of quadrivalent conjugate vaccine in adolescence is recommended in different countries, including the USA [94] and the UK [95]. Given the countryspecific particularities of meningococcal vaccination programs, several studies have explored the use of a MenACWY-CRM booster dose in adolescents primed with different mono- or quadrivalent meningococcal conjugate vaccines. A MenACWY-CRM booster dose administered 3-6 years after vaccination with either MenACWY-DT or MenACWY-CRM induced a fast and robust anamnestic response, from as early as 6 days [68, 72]; evidence has also been generated for persistence of antibody titers following booster administration [96]. In MenCprimed teenagers who received a booster dose of MenACWY-CRM 13 years after primary vaccination, boostability of the immune response against serogroup C was demonstrated [91].

\section{CO-ADMINISTRATION OF MENACWY-CRM WITH OTHER VACCINES}

\section{Co-administration with Routine Childhood/Adolescent Vaccinations}

Co-administration of vaccines targeting different infectious agents has the benefit of reducing the number of vaccination visits to a minimum, thus facilitating the implementation of busy infant vaccination schedules. Therefore, evidence is needed to show that vaccines can be administered during the same visit without any significant negative impact on the safety and immunogenicity of either vaccine [52].

In infants and toddlers, no clinically relevant vaccine interactions and/or impact on vaccine reactogenicity and safety were observed when MenACWY-CRM was co-administered with routine vaccines such as hepatitis $A$ and $B$ vaccines (HAV, HBV), combined diphtheria-tetanus-acellular pertussis vaccine (DTaP), inactivated poliomyelitis vaccine (IPV), vaccines against $H$. influenzae type $\mathrm{b}(\mathrm{Hib})$, combined DTaP-IPV-HBV/Hib, 7- and 13-valent pneumococcal conjugate vaccines (PCV7, PCV13), measles-mumps-rubella (MMR), varicella (V) and combined MMRV vaccines and rotavirus vaccine [50-54, 76, 77] (Fig. 4).

Immunological interference may arise when conjugated polysaccharide vaccines using TT, DT and CRM as carrier proteins are administered after tetanus-diphtheria-containing vaccines. This is thought to be the result of an antigenic competition between the polysaccharide and the carrier protein epitopes, resulting in an increased antibody response to the carrier and a decreased response to the conjugated polysaccharides [97]. To explore whether such interference also appears in the case of MenACWY-CRM, studies designed to identify whether immune responses against the four vaccine serogroups are influenced by the concomitant or sequential administration of MenACWY-CRM with tetanus-diphtheria-containing vaccines have been conducted in adolescents and adults. In Korean military recruits, while administration of tetanus-diphtheria toxoids (Td) 3 days before MenACWY-CRM led to lower antibody levels against MenA and C, seroprotection rates against MenC were not significantly influenced [78], and the differences are not considered to be clinically relevant. When co-administered with the tetanusdiphtheria-acellular pertussis vaccine (Tdap), no interference of immune responses against either of the four meningococcal serogroups was observed in adolescents and young adults [76]. Similarly, no clinically relevant vaccine interactions or safety concerns were observed following concomitant administration of MenACWY-CRM, Tdap and HPV vaccine in 


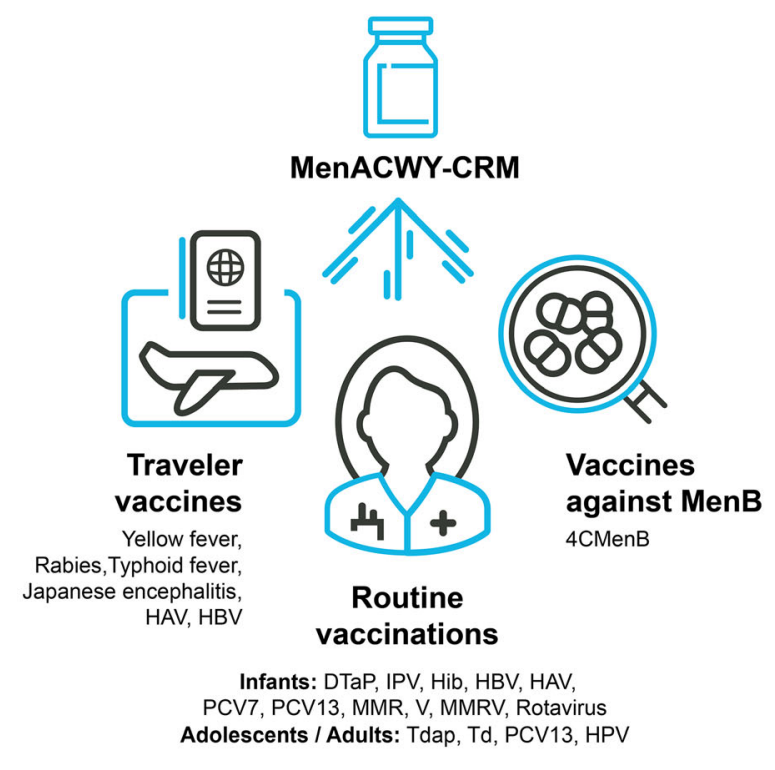

Fig. 4 Available evidence on the co-administration of MenACWY-CRM with other vaccines. MenACWY-CRM quadrivalent meningococcal vaccine against serogroups $\mathrm{A}$, $\mathrm{C}, \mathrm{W}$ and $\mathrm{Y}$, conjugated to the nontoxic mutant of diphtheria toxin, DTaP combined diphtheria, pertussis and tetanus vaccine, $I P V$ inactivated poliomyelitis vaccine, $H i b$ Haemophilus influenzae type b vaccine, $H B V$ hepatitis $\mathrm{B}$ vaccine, $H A V$ hepatitis A vaccine, $P C V 7$ 7-valent pneumococcal conjugate vaccine, PCV13 13-valent

adolescents [76, 98, 99]. Co-administration of MenACWY-CRM with Tdap and PCV13 induced similar serogroup $\mathrm{W}$-specific immune responses and was well tolerated, regardless of prior, concurrent or sequential administration of Tdap in Australian adults $[79,80]$.

Based on these results that show no significant interference of the immune responses against the vaccine antigens after completion of the vaccination course, concurrent administration of MenACWY-CRM and routine adolescent and adult vaccines, such as tetanus-diphtheriacontaining vaccines, HPV vaccine and pneumococcal vaccines, is generally considered as both immunogenic and practical [76, 80, 100].

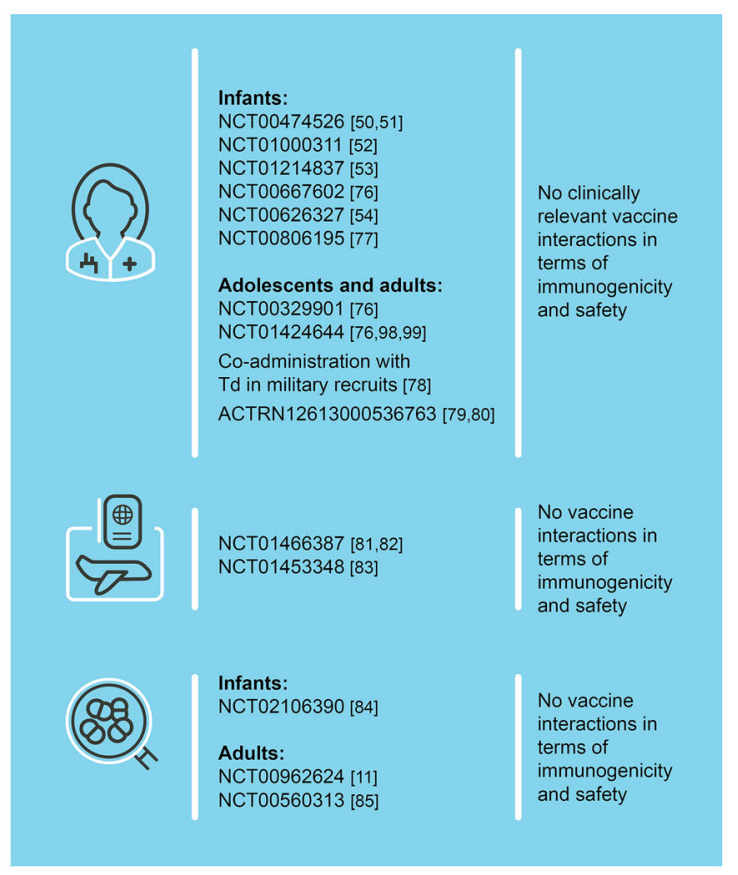

pneumococcal conjugate vaccine, $M M R$ measles-mumpsrubella vaccine, $V$ varicella vaccine, $M M R V$ measlesmumps-rubella-varicella vaccine, Rotavirus rotavirus vaccine, Tdap tetanus-diphtheria-acellular pertussis vaccine, $T d$ tetanus-diphtheria toxoid, $H P V$ human papillomavirus vaccine, MenB Neisseria meningitidis serogroup B, $4 C M e n B$ multicomponent vaccine against meningococcal serogroup B

\section{Co-administration with Traveler Vaccines}

For travelers, concomitant administration of multiple vaccines is essential for maximizing protection against diseases within the often limited timeframe available before the start of travel. However, assessment of potential interactions between vaccines is required before routinely recommending co-administration [76]. In adolescents or adults, co-administration of MenACWY-CRM with several traveler vaccines (including vaccines against typhoid fever, yellow fever, Japanese encephalitis and rabies), $\mathrm{HAV}, \mathrm{HBV}$ or the combined HAV-HBV vaccines did not interfere with the immunogenicity or safety of the individual vaccines [81-83] (Fig. 4). 


\section{Co-administration with Vaccines Against MenB}

Development of $4 \mathrm{CMenB}$, a vaccine against meningococcal serogroup $B$, has broadened the spectrum of vaccine-preventable IMD-causing meningococcal serogroups. The first studies assessing the sequential administration of a three-dose schedule of $4 \mathrm{CMenB}$, followed by MenACWY-CRM after 1 month [85], and the concomitant administration of MenACWYCRM with the first dose of $4 \mathrm{CMenB}$ [11] were conducted in laboratory workers routinely exposed to meningococcal isolates. Results of these studies revealed no immunological interference between 4CMenB and MenACWY-CRM and their co-administration also showed an acceptable safety profile $[11,85]$.

Co-administration of quadrivalent and serogroup B meningococcal vaccines in infants has the benefit of providing immunization against five of the most prevalent meningococcal serogroups during the first year of life, when the risk of IMD is the highest. Co-administration of 4CMenB and MenACWY-CRM at 3, 5, 7 and 13 months of age demonstrated an acceptable safety profile, with no notable increase in reactogenicity observed in participants who received both vaccines compared to those who received $4 \mathrm{CMenB}$ only; immune responses elicited following co-administration were noninferior compared to those following separate administration [84].

These data confirm that 4CMenB and MenACWY-CRM are safe and immunogenic with no interference when administered during the same vaccination visit. This combination is successful in inducing seroprotection in individuals who are at increased risk of IMD by virtue of their young age or their occupation (Fig. 4).

\section{EFFECT OF MENACWY-CRM ON CARRIAGE AND TRANSMISSION}

The rate of meningococcal carriage varies among the different age groups in a population and is strongly influenced by factors such as living in crowded conditions (e.g., college dormitories, military camps) or various social mixing behaviors. In developed countries, carriage rate peaks in adolescents and young adults, while in developing countries, carriage appears to be more common in early childhood and adulthood, with carriage rates being more evenly distributed across age groups [101, 102]. Since asymptomatic carriers are the main source of transmission, reducing the nasopharyngeal carriage of pathogenic meningococci has the potential to significantly reduce transmission [34].

Significant decreases in cross-sectional carriage rates of vaccine serogroups have been previously documented following mass vaccination with monovalent vaccines against MenC and MenA in the UK and sub-Saharan Africa, respectively [103-106]. To date, two studies have evaluated the impact of MenACWY-CRM vaccination on carriage. In students from the UK aged between 18 and 24 years, administration of MenACWY-CRM resulted in a significant decrease of $36 \%$ in MenC, $\mathrm{W}$ and $\mathrm{Y}$ carriage rates during the 12 months after vaccination [70]. In Poland, carriage rates for serogroups C, $\mathrm{W}$ and $\mathrm{Y}$ were significantly lower in professional soldiers (considered to be a high-exposure group) who had been vaccinated with MenACWY-CRM (1\%) compared to their unvaccinated counterparts (10\%) [9].

\section{REAL-WORLD EVIDENCE OF MENACWY-CRM IMPACT}

As IMD is an uncommon and life-threatening disease, the efficacy of MenACWY-CRM could not be assessed through randomized controlled trial designs and its licensure relied on immunological correlates of protection. Accordingly, observational studies are the only available method to assess the vaccine's effect in reducing the incidence and risk of IMD caused by serogroups $\mathrm{A}, \mathrm{C}, \mathrm{W}$ and $\mathrm{Y}$.

A recent study in a high-exposure groupthe Armed Forces in South Korea-showed a reduction of $88 \%$ in meningococcal disease incidence after $95 \%$ of soldiers (amounting to a 
population of 1624,000 person-years) were vaccinated with MenACWY-CRM during a 4-year period [107]. No cases of IMD resulting from serogroups $\mathrm{A}, \mathrm{C}, \mathrm{W}$ and $\mathrm{Y}$, and no deaths occurred during the study period, compared to four deaths in the 5 years before vaccination was implemented. No new safety signals were detected, and the safety profile of the vaccine matched the one observed in clinical trials. As soldiers only stayed on duty for 2 years, the duration of protection could only be demonstrated for this follow-up period.

\section{CONCLUSION}

As more time passes since the introduction of NIPs in an increasing number of countries, the population-level effects of immunization are becoming clearer. These effects contribute to selecting the best approach for reducing IMD incidence. While access to healthcare services may currently be challenging in many countries due to the COVID-19 pandemic, it is essential to prioritize routine immunization, since high vaccination rates help to ensure that no additional pressure is placed on the already overloaded healthcare systems; guidance from the World Health Organization (WHO) also recommends countries to prioritize routine immunization of children and urgent catchups. Especially in the context of the increased contact and socialization that will follow the lifting of lockdowns and the reopening of schools, accent should be placed on protecting children and adolescents, two age groups who are at increased risk of IMD. This is also important since initial non-specific symptoms of IMD might resemble those of COVID-19, potentially preventing early diagnosis, which in the case of IMD, is essential for a fast and appropriate treatment.

With the continuously evolving epidemiology of meningococcal serogroups responsible for IMD, protection against the most common $N$. meningitidis serogroups becomes crucial. MenACWY-CRM can play an important role in generating such a protection, with the added benefit of being easily integrated into current vaccination programs. Co-administration of
MenACWY-CRM with 4CMenB will help protect against five of the most common serogroups responsible for IMD, thus facilitating the implementation of public health strategies to fight this uncommon but life-threatening disease.

\section{ACKNOWLEDGEMENTS}

Funding. This paper was funded by GlaxoSmithKline Biologicals SA. GlaxoSmithKline Biologicals SA was involved in all stages of the conduct and analysis of the study and covered all costs associated with the development and the publishing of the present manuscript.

Medical Writing, Editorial, and Other Assistance. Authors thank Modis c/o GSK for editorial assistance and manuscript coordination. Timea Kiss provided medical writing support, Sonja Sachse and Adrian Kremer coordinated the manuscript development and provided editorial support.

Authorship. All named authors meet the International Committee of Medical Journal Editors (ICMJE) criteria for authorship for this article, take responsibility for the integrity of the work as a whole, and have given their approval for this version to be published.

Authorship Contributions. All authors participated in the development and the review of the manuscript and approved the final submitted version.

Disclosures. All authors are employed by the GSK Group of Companies, and Véronique Abitbol, Rafik Bekkat-Berkani, Michele Pellegrini, and Lamine Soumahoro also hold shares in the GSK Group of Companies. All authors declare no non-financial conflict of interest.

Compliance with Ethics Guidelines. This article is based on previously conducted studies and does not contain any new studies with human participants or animals performed by any of the authors. 
Data Availability. Data sharing is not applicable to this article as no datasets were generated or analyzed during the current study.

Trademark Statement. Menveo is a trademark owned by or licensed to the GSK group of companies. Nimenrix is a trademark owned by Pfizer. Menactra and MenQuadfi are trademarks owned by Sanofi Pasteur.

Open Access. This article is licensed under a Creative Commons Attribution-NonCommercial 4.0 International License, which permits any non-commercial use, sharing, adaptation, distribution and reproduction in any medium or format, as long as you give appropriate credit to the original author(s) and the source, provide a link to the Creative Commons licence, and indicate if changes were made. The images or other third party material in this article are included in the article's Creative Commons licence, unless indicated otherwise in a credit line to the material. If material is not included in the article's Creative Commons licence and your intended use is not permitted by statutory regulation or exceeds the permitted use, you will need to obtain permission directly from the copyright holder. To view a copy of this licence, visit http://creativecommons.org/licenses/by$\mathrm{nc} / 4.0 /$.

\section{REFERENCES}

1. Gabutti G, Stefanati A, Kuhdari P. Epidemiology of Neisseria meningitidis infections: case distribution by age and relevance of carriage. J Prev Med Hyg. 2015;56:E116-20.

2. Borrow R, Balmer P, Miller E. Meningococcal surrogates of protection-serum bactericidal antibody activity. Vaccine. 2005;23:2222-7.

3. Olbrich KJ, Müller D, Schumacher S, Beck E, Meszaros K, Koerber F. Systematic review of invasive meningococcal disease: sequelae and quality of life impact on patients and their caregivers. Infect Dis Ther. 2018;7:421-38.

4. Wang B, Santoreneos R, Giles L, Haji Ali Afzali H, Marshall $H$. Case fatality rates of invasive meningococcal disease by serogroup and age: a systematic review and meta-analysis. Vaccine. 2019;37:2768-82.

5. Goldschneider I, Gotschlich EC, Artenstein MS. Human immunity to the meningococcus. I. The role of humoral antibodies. J Exp Med. 1969;129: 1307-26.

6. Pace D, Pollard AJ, Messonier NE. Quadrivalent meningococcal conjugate vaccines. Vaccine. 2009;27(Suppl 2):B30-41.

7. Becerra-Culqui TA, Sy LS, Ackerson BK, et al. Safety of quadrivalent meningococcal conjugate vaccine in infants and toddlers 2 to 23 -months old. Vaccine. 2020;38:228-34.

8. Brigham KS, Sandora TJ. Neisseria meningitidis: epidemiology, treatment and prevention in adolescents. Curr Opin Pediatr. 2009;21:437-43.

9. Korzeniewski K, Skoczyńska A, Guzek A, et al. Effectiveness of immunoprophylaxis in suppressing carriage of Neisseria meningitidis in the military environment. Adv Exp Med Biol. 2015;836:19-28.

10. Wilder-Smith A. Meningococcal vaccine in travelers. Curr Opin Infect Dis. 2007;20:454-60.

11. Findlow J, Bai X, Findlow $\mathrm{H}$, et al. Safety and immunogenicity of a four-component meningococcal group B vaccine (4CMenB) and a quadrivalent meningococcal group ACWY conjugate vaccine administered concomitantly in healthy laboratory workers. Vaccine. 2015;33:3322-30.

12. Rivero-Calle I, Raguindin PF, Gómez-Rial J, Rodriguez-Tenreiro C, Martinón-Torres F. Meningococcal group B vaccine for the prevention of invasive meningococcal disease caused by Neisseria meningitidis serogroup B. Infect Drug Resist. 2019;12: 3169-88.

13. Halperin SA, Bettinger JA, Greenwood B, et al. The changing and dynamic epidemiology of meningococcal disease. Vaccine. 2012;30(Suppl 2):B26-36.

14. Public Health Agency of Canada. Vaccine preventable disease: surveillance report to December 31, 2015. 2017. [Accessed on Oct 15, 2020]. https:// www.canada.ca/en/public-health/services/ publications/healthy-living/vaccine-preventabledisease-surveillance-report-december-31-2015. html\#a64.

15. Memish Z, Al Hakeem R, Al Neel O, Danis K, Jasir A, Eibach D. Laboratory-confirmed invasive meningococcal disease: effect of the Hajj vaccination policy, Saudi Arabia, 1995 to 2011. Euro Surveill. 2013;18: 20581. 
16. National Institute for Communicable Diseases. GERMS-SA annual report 2017. 2017. [Accessed on Oct 15, 2020]. https://www.nicd.ac.za/wp-content/ uploads/2018/08/GERMS-SA-AR-2017-final.pdf.

17. Australian Government Department of Health. Invasive meningococcal disease national surveillance report, Quarter 4, 2018. 2018. [Accessed on Nov 02, 2020]. https://www1.health.gov.au/ internet/main/publishing.nsf/Content/ 5FEABC4B495BDEC1CA25807D001327FA/\$File/ 1Oct-31Dec19-qrt3-IMD.pdf.

18. Environmental Science Research. Invasive meningococcal disease report. 2019. [Accessed on Dec 08, 2020]. https://surv.esr.cri.nz/PDF_ surveillance/MeningococcalDisease/2018/

MeningococcalDisease_wk512018-wk12019.pdf.

19. Centers for Disease Control and Prevention. Enhanced meningococcal disease surveillance report, 2017. [Accessed on Oct 14, 2020]. https:// www.cdc.gov/meningococcal/downloads/NCIRDEMS-Report-2017.pdf.

20. Instituto de Salud Pública de Chile. Informe de resultados de vigilancia de laboratorio enfermedad invasora Neisseria meningitidis. 2019. [Accessed on Dec 02, 2020]. http://www.ispch.cl/sites/default/ files/Informe $\% 20$ Neisseria $\% 20$ meningitidis $\% 20 \%$ 20SE\%201-52-2019\%20v2.pdf.

21. European Centre for Disease Prevention and Control. Invasive meningococcal disease - Annual epidemiological report for 2017. 2019. [Accessed on Dec 02, 2020]. https://www.ecdc.europa.eu/en/ publications-data/invasive-meningococcal-diseaseannual-epidemiological-report-2017.

22. World Health Organization. Weekly epidemiological record. 2016. [Accessed on Jan 12, 2021]. https:// www.who.int/wer/2016/wer9116.pdf?ua=1.

23. National Institute of Infectious Diseases. Infectious agents surveillance report. 2018. [Accessed on Dec 02, 2020]. https://www.niid.go.jp/niid/en/iasrvol39-e/7803-idx455-e.html.

24. Ministry of Health/SVS. Notifiable Diseases Information System - SINAN Net. [Accessed on Jan 12, 2021]. http://tabnet.datasus.gov.br/cgi/tabcgi. exe?sinannet/cnv/meninbr.def.

25. Ceyhan M, Ozsurekci Y, Tanır Basaranoglu S, et al. Multicenter hospital-based prospective surveillance study of bacterial agents causing meningitis and seroprevalence of different serogroups of Neisseria meningitidis, Haemophilus influenzae type $\mathrm{b}$, and Streptococcus pneumoniae during 2015 to 2018 in Turkey. mSphere. 2020;5:e00060-20.
26. National Institute of Infectious Diseases. Information on the surveillance of pneumonia and bacterial meningitis. SIREVA II. OPS. Neisseria meningitidis. 2018. [Accessed on Jan 12, 2021]. http:// antimicrobianos.com.ar/ATB/wp-content/uploads/ 2019/03/Tablas-SIREVA-II-Nm-2018.pdf.

27. Instituto Nacional de Salud. Vigilancia por laboratorio Neisseria meningitidis 2010-2019. [Accessed on Mar 15, 2021]. https://www.ins.gov.co/buscadoreventos/Informacin\%20de\%20laboratorio/ Vigilancia-por-laboratorio-N-meningitidis-20102019.pdf.

28. Dretler AW, Rouphael NG, Stephens DS. Progress toward the global control of Neisseria meningitidis: 21st century vaccines, current guidelines, and challenges for future vaccine development. Hum Vaccin Immunother. 2018;14:1146-60.

29. Pizza M, Bekkat-Berkani R, Rappuoli R. Vaccines against meningococcal diseases. Microorganisms. 2020;8:1521.

30. Bröker M, Dull PM, Rappuoli R, Costantino P. Chemistry of a new investigational quadrivalent meningococcal conjugate vaccine that is immunogenic at all ages. Vaccine. 2009;27:5574-80.

31. Pace D. MenACWY-CRM, a novel quadrivalent glycoconjugate vaccine against Neisseria meningitidis for the prevention of meningococcal infection. Curr Opin Mol Ther. 2009;11:692-706.

32. Cooper B, DeTora L, Stoddard J. Menveo ${ }^{\circledR}$ : a novel quadrivalent meningococcal CRM197 conjugate vaccine against serogroups $\mathrm{A}, \mathrm{C}, \mathrm{W}-135$ and $\mathrm{Y}$. Expert Rev Vaccines. 2011;10:21-33.

33. Gotschlich EC, Goldschneider I, Artenstein MS. Human immunity to the meningococcus. IV. Immunogenicity of group $\mathrm{A}$ and group $\mathrm{C}$ meningococcal polysaccharides in human volunteers. J Exp Med. 1969;129:1367-84.

34. Trotter CL, Maiden MCJ. Meningococcal vaccines and herd immunity: lessons learned from serogroup C conjugate vaccination programs. Expert Rev Vaccines. 2009;8:851-61.

35. Pace D. Quadrivalent meningococcal ACYW-135 glycoconjugate vaccine for broader protection from infancy. Expert Rev Vaccines. 2009;8:529-42.

36. Pace D, Pollard AJ. Meningococcal A, C, Y and $\mathrm{W}$-135 polysaccharide-protein conjugate vaccines. Arch Dis Child. 2007;92:909-15.

37. Ward J, Berkowitz C, Pescetti J, Burkart K, Samuelson $\mathrm{O}$, Gordon L. Enhanced immunogenicity in young infants of a new Haemophilus influenzae type b (Hib) capsular polysaccharide(PRP)-diphtheria 
toxoid(D) conjugate vaccine. Pediatr Res. 1984;18: 287.

38. Morris SK, Moss WJ, Halsey N. Haemophilus influenzae type b conjugate vaccine use and effectiveness. Lancet Infect Dis. 2008;8:435-43.

39. Goldblatt D. Conjugate vaccines. Clin Exp Immunol. 2000;119:1-3.

40. Beuvery EC, Miedema F, van Delft RW, Haverkamp J, Tiesjema RH, Nagel J. Vaccine potential of meningococcal group $\mathrm{C}$ polysaccharide-tetanus toxoid conjugate. J Infect. 1983;6:247-55.

41. Balmer P, Borrow R, Miller E. Impact of meningococcal $C$ conjugate vaccine in the UK. J Med Microbiol. 2002;51:717-22.

42. Deeks ED. Meningococcal quadrivalent (serogroups A, C, W135, and Y) conjugate vaccine (Menveo): in adolescents and adults. BioDrugs. 2010;24:287-97.

43. Plotkin SA. Immunologic correlates of protection induced by vaccination. Pediatr Infect Dis J. 2001;20:63-75.

44. Borrow R, Taha MK, Giuliani MM, Pizza M, Banzhoff A, Bekkat-Berkani R. Methods to evaluate serogroup B meningococcal vaccines: From predictions to real-world evidence. J Infect. 2020;81:862-72.

45. Frasch CE, Borrow R, Donnelly J. Bactericidal antibody is the immunologic surrogate of protection against meningococcal disease. Vaccine. 2009;27(Suppl 2):B112-6.

46. Maslanka SE, Gheesling LL, Libutti DE, et al. Standardization and a multilaboratory comparison of Neisseria meningitidis serogroup A and C serum bactericidal assays. The Multilaboratory Study Group. Clin Diagn Lab Immunol. 1997;4:156-67.

47. Luo W, Arkwright PD, Borrow R. Antibody persistence following meningococcal ACWY conjugate vaccine licensed in the European Union by age group and vaccine. Expert Rev Vaccines. 2020;19: 745-54.

48. Cepem. Información sobre Vacunas - meningococo [Information about vaccines - meningococcal]. [Accessed on Apr 08, 2021]. https://www.cepem. com.ar/doku/doku.php?id=meningococo.

49. Office fédéral de la santé publique, Commission fédérale pour les vaccinations. Plan de vaccination suisse 2020 [Swiss vaccination plan 2020]. [Accessed on Jan 07, 2021]. https://www.bag.admin.ch/bag/ $\mathrm{fr} /$ home/gesund-leben/gesundheitsfoerderung-undpraevention/impfungen-prophylaxe/ schweizerischer-impfplan.html.
50. Klein NP, Reisinger KS, Johnston W, et al. Safety and immunogenicity of a novel quadrivalent meningococcal CRM-conjugate vaccine given concomitantly with routine vaccinations in infants. Pediatr Infect Dis J. 2012;31:64-71.

51. Tregnaghi M, Lopez P, Stamboulian D, et al. Immunogenicity and safety of a quadrivalent meningococcal polysaccharide CRM conjugate vaccine in infants and toddlers. Int $\mathrm{J}$ Infect Dis. 2014;26:22-30.

52. Nolan TM, Nissen MD, Naz A, et al. Immunogenicity and safety of a CRM-conjugated meningococcal ACWY vaccine administered concomitantly with routine vaccines starting at 2 months of age. Hum Vaccin Immunother. 2014;10:280-9.

53. Block SL, Shepard J, Garfield H, et al. Immunogenicity and safety of a 3- and 4-dose vaccination series of a meningococcal ACWY conjugate vaccine in infants: results of a phase $3 \mathrm{~b}$, randomized, openlabel trial. Pediatr Infect Dis J. 2016;35:e48-59.

54. Klein NP, Shepard J, Bedell L, Odrljin T, Dull P. Immunogenicity and safety of a quadrivalent meningococcal conjugate vaccine administered concomitantly with measles, mumps, rubella, varicella vaccine in healthy toddlers. Vaccine. 2012;30: 3929-36.

55. Lee HJ, Jo DS, Kim YK, et al. One-year antibody persistence and safety of a 4-dose schedule of MenACWY-CRM in healthy infants from South Korea. Clin Exp Vaccine Res. 2019;8:94-102.

56. Yoo BW, Jung HL, Byeon YS, et al. Results from a large post-marketing safety surveillance study in the Republic of Korea with a quadrivalent meningococcal CRM-conjugate vaccine in individuals aged 2 months-55 years. Hum Vaccin Immunother. 2020;16:1260-7.

57. Bona G, Castiglia P, Zoppi G, et al. Safety and immunogenicity of a CRM or TT conjugated meningococcal vaccine in healthy toddlers. Vaccine. 2016;34:3363-70.

58. Safety and immunogenicity of Novartis meningococcal ACWY conjugate vaccine in healthy children aged 12-59 months. [Accessed on Sep 23, 2020]. https://clinicaltrials.gov/ct2/show/results/ NCT00310817.

59. Myers TR, McNeil MM, Ng CS, Li R, Lewis PW, Cano MV. Adverse events following quadrivalent meningococcal CRM-conjugate vaccine (Menveo $\left.{ }^{\circledR}\right)$ reported to the Vaccine Adverse Event Reporting system (VAERS), 2010-2015. Vaccine. 2017;35: $1758-63$. 
60. Johnston W, Essink B, Kirstein J, et al. Comparative assessment of a single dose and a 2-dose vaccination series of a quadrivalent meningococcal CRM-conjugate vaccine (MenACWY-CRM) in children 2-10 years of age. Pediatr Infect Dis J. 2016;35:e19-27.

61. Lalwani S, Agarkhedkar S, Gogtay N, et al. Safety and immunogenicity of an investigational meningococcal ACWY conjugate vaccine (MenACWY-CRM) in healthy Indian subjects aged 2 to 75 years. Int J Infect Dis. 2015;38:36-42.

62. Huang LM, Chiu NC, Yeh SJ, Bhusal C, Arora AK. Immunogenicity and safety of a single dose of a CRM-conjugated meningococcal ACWY vaccine in children and adolescents aged $2-18$ years in Taiwan: results of an open label study. Vaccine. 2014;32: 5177-84.

63. Ilyina N, Kharit S, Namazova-Baranova L, et al. Safety and immunogenicity of meningococcal ACWY CRM197-conjugate vaccine in children, adolescents and adults in Russia. Hum Vaccin Immunother. 2014;10:2471-81.

64. Block SL, Christensen S, Verma B, et al. Antibody persistence 5 years after vaccination at 2 to 10 years of age with quadrivalent MenACWY-CRM conjugate vaccine, and responses to a booster vaccination. Vaccine. 2015;33:2175-82.

65. Klein NP, Block SL, Essink B, Barbi S, Smolenov I, Keshavan P. Antibody persistence and booster response following MenACWY-CRM vaccination in children as assessed by two different assay methods. Vaccine. 2019;37:4460-7.

66. Tartof SY, Sy LS, Ackerson BK, et al. Safety of quadrivalent meningococcal conjugate vaccine in children 2-10 years. Pediatr Infect Dis J. 2017;36: 1087-92.

67. Lee HJ, Chung MH, Kim WJ, et al. Immunogenicity and safety of a novel quadrivalent meningococcal conjugate vaccine (MenACWY-CRM) in healthy Korean adolescents and adults. Int J Infect Dis. 2014;28:204-10.

68. Baxter R, Reisinger K, Block SL, Izu A, Odrljin T, Dull $P$. Antibody persistence and booster response of a quadrivalent meningococcal conjugate vaccine in adolescents. J Pediatr. 2014;164:1409-15.e4.

69. Jacobson RM, Jackson LA, Reisinger K, Izu A, Odrljin T, Dull PM. Antibody persistence and response to a booster dose of a quadrivalent conjugate vaccine for meningococcal disease in adolescents. Pediatr Infect Dis J. 2013;32:e170-7.

70. Read RC, Baxter D, Chadwick DR, et al. Effect of a quadrivalent meningococcal ACWY glycoconjugate or a serogroup $\mathrm{B}$ meningococcal vaccine on meningococcal carriage: an observer-blind, phase 3 randomised clinical trial. Lancet. 2014;384: 2123-31.

71. Mayet A, Duron S, Meynard JB, Koeck JL, Deparis X, Migliani R. Surveillance of adverse events following vaccination in the French armed forces, 2011-2012. Public Health. 2015;129:763-8.

72. Tipton M, Daly W, Senders S, et al. MenACWY-CRM conjugate vaccine booster dose given 4-6 years after priming: results from a phase IIIb, multicenter, open label study in adolescents and adults. Vaccine. 2019;37:6171-9.

73. Becerra-Culqui TA, Sy LS, Ackerson BK, et al. Safety of MenACWY-CRM vaccine exposure during pregnancy. Vaccine. 2020;38:2683-90.

74. Tseng HF, Sy LS, Ackerson BK, et al. Safety of quadrivalent meningococcal conjugate vaccine in 11- to 21-year-olds. Pediatrics. 2017;139: e20162084.

75. Becerra-Culqui TA, Sy LS, Solano Z, Tseng HF. Realworld evidence of quadrivalent meningococcal conjugate vaccine safety in the United States: a systematic review. Hum Vaccin Immunother. 2020. https://doi.org/10.1080/21645515.2020.1829412.

76. Gasparini R, Tregnaghi M, Keshavan P, Ypma E, Han L, Smolenov I. Safety and immunogenicity of a quadrivalent meningococcal conjugate vaccine and commonly administered vaccines after coadministration. Pediatr Infect Dis J. 2016;35:81-93.

77. Abdelnour A, Silas PE, Lamas MRV, et al. Safety of a quadrivalent meningococcal serogroups A, C, W and $\mathrm{Y}$ conjugate vaccine (MenACWY-CRM) administered with routine infant vaccinations: results of an open-label, randomized, phase $3 \mathrm{~b}$ controlled study in healthy infants. Vaccine. 2014;32:965-72.

78. Kim HW, Park IH, You S, et al. Immunogenicity of MenACWY-CRM in Korean military recruits: influence of tetanus-diphtheria toxoid vaccination on the vaccine response to MenACWY-CRM. Yonsei Med J. 2016;57:1511-6.

79. Tashani M, Alfelali M, Barasheed O, et al. Effect of Tdap when administered before, with or after the 13-valent pneumococcal conjugate vaccine (coadministered with the quadrivalent meningococcal conjugate vaccine) in adults: a randomised controlled trial. Vaccine. 2016;34:5929-37.

80. Tashani M, Badahdah AM, Alfelali M, et al. Effect on meningococcal serogroup $\mathrm{W}$ immunogenicity when Tdap was administered prior, concurrent or subsequent to the quadrivalent (ACWY) meningococcal CRM(197)-conjugate vaccine in adult Hajj 
pilgrims: a randomised controlled trial. Vaccine. 2019;37:3562-7.

81. Alberer M, Burchard G, Jelinek T, et al. Co-administration of a meningococcal glycoconjugate ACWY vaccine with travel vaccines: a randomized, openlabel, multi-center study. Travel Med Infect Dis. 2014;12:485-93.

82. Alberer M, Burchard G, Jelinek T, et al. Safety and immunogenicity of typhoid fever and yellow fever vaccines when administered concomitantly with quadrivalent meningococcal ACWY glycoconjugate vaccine in healthy adults. J Travel Med. 2015;22: $48-56$.

83. Alberer M, Burchard G, Jelinek T, et al. Immunogenicity and safety of concomitant administration of a combined hepatitis $\mathrm{A} / \mathrm{B}$ vaccine and a quadrivalent meningococcal conjugate vaccine in healthy adults. J Travel Med. 2015;22:105-14.

84. Macias Parra M, Gentile A, Vazquez Narvaez JA, et al. Immunogenicity and safety of the 4CMenB and MenACWY-CRM meningococcal vaccines administered concomitantly in infants: a phase $3 \mathrm{~b}$, randomized controlled trial. Vaccine. 2018;36: 7609-17.

85. Kimura A, Toneatto D, Kleinschmidt A, Wang H, Dull P. Immunogenicity and safety of a multicomponent meningococcal serogroup $\mathrm{B}$ vaccine and a quadrivalent meningococcal CRM197 conjugate vaccine against serogroups $\mathrm{A}, \mathrm{C}, \mathrm{W}-135$, and $\mathrm{Y}$ in adults who are at increased risk for occupational exposure to meningococcal isolates. Clin Vaccine Immunol. 2011;18:483-6.

86. Menveo. Summary of product characteristics. [Accessed on Sep 23, 2020]. https://www.ema. europa.eu/en/documents/product-information/ menveo-epar-product-information_en.pdf.

87. Khatami A, Snape MD, Davis E, et al. Persistence of the immune response at 5 years of age following infant immunisation with investigational quadrivalent MenACWY conjugate vaccine formulations. Vaccine. 2012;30:2831-8.

88. Blanchard-Rohner G, Snape MD, Kelly DF, et al. The B-cell response to a primary and booster course of MenACWY-CRM $_{197}$ vaccine administered at 2, 4 and 12 months of age. Vaccine. 2013;31:2441-8.

89. Blanchard-Rohner G, Snape MD, Kelly DF, et al. Seroprevalence and placental transmission of maternal antibodies specific for Neisseria meningitidis Serogroups A, C, Y and W135 and influence of maternal antibodies on the immune response to a primary course of MenACWY-CRM vaccine in the United Kingdom. Pediatr Infect Dis J. 2013;32: 768-76.
90. Read RC, Dull P, Bai X, et al. A phase III observerblind randomized, controlled study to evaluate the immune response and the correlation with nasopharyngeal carriage after immunization of university students with a quadrivalent meningococcal ACWY glycoconjugate or serogroup B meningococcal vaccine. Vaccine. 2017;35:427-34.

91. Ishola DA, Andrews N, Waight P, et al. Randomized trial to compare the immunogenicity and safety of a CRM or TT conjugated quadrivalent meningococcal vaccine in teenagers who received a CRM or TT conjugated serogroup $\mathrm{C}$ vaccine at preschool age. Pediatr Infect Dis J. 2015;34:865-74.

92. Ramasamy MN, Clutterbuck EA, Haworth K, et al. Randomized clinical trial to evaluate the immunogenicity of quadrivalent meningococcal conjugate and polysaccharide vaccines in adults in the United Kingdom. Clin Vaccine Immunol. 2014;21:1164-8.

93. Giuliani MM, Biolchi A, Keshavan P, et al. Bactericidal antibodies against hypervirulent Neisseria meningitidis $\mathrm{C}$ field strains following MenC-CRM or MenACWY-CRM priming and MenACWY-CRM booster in children. Hum Vaccin Immunother. 2021;17:1442-9 (Published online in 2020).

94. Cohn AC, MacNeil JR, Clark TA, et al. Prevention and control of meningococcal disease: recommendations of the Advisory Committee on Immunization Practices (ACIP). MMWR Recomm Rep. 2013;62:1-28.

95. Green Book. Chapter 22: Meningococcal. [Accessed on Jan 12, 2021]. https://assets.publishing.service. gov.uk/government/uploads/system/uploads/ attachment_data/file/554011/Green_Book_ Chapter_22.pdf.

96. Baxter R, Reisinger K, Block SL, et al. Antibody persistence after primary and booster doses of a quadrivalent meningococcal conjugate vaccine in adolescents. Pediatr Infect Dis J. 2014;33:1169-76.

97. Pobre K, Tashani M, Ridda I, Rashid H, Wong M, Booy R. Carrier priming or suppression: understanding carrier priming enhancement of antipolysaccharide antibody response to conjugate vaccines. Vaccine. 2014;32:1423-30.

98. Gasparini R, Johnston W, Conversano $\mathrm{M}$, et al. Immunogenicity and safety of combined tetanus, reduced diphtheria, acellular pertussis vaccine when co-administered with quadrivalent meningococcal conjugate and human papillomavirus vaccines in healthy adolescents. J Vaccines Vaccin. 2014;5:3.

99. Miao Y, Mzolo T, Pellegrini M. Immunogenicity of a quadrivalent human papillomavirus vaccine when co-administered with tetanus-reduced diphtheria- 
acellular pertussis and quadrivalent meningococcal conjugate vaccines in healthy adolescents: results from a randomized, observer-blind, controlled trial. Infect Dis Ther. 2019;8:335-41.

100. Mbaeyi SA, Bozio CH, Duffy J, et al. Meningococcal vaccination: recommendations of the Advisory Committee on Immunization Practices, United States, 2020. MMWR Recomm Rep. 2020;69:1-41.

101. Balmer P, Burman C, Serra L, York LJ. Impact of meningococcal vaccination on carriage and disease transmission: a review of the literature. Hum Vaccin Immunother. 2018;14:1118-30.

102. Trotter CL, Greenwood BM. Meningococcal carriage in the African meningitis belt. Lancet Infect Dis. 2007;7:797-803.

103. Maiden MC, Ibarz-Pavón AB, Urwin R, et al. Impact of meningococcal serogroup $C$ conjugate vaccines on carriage and herd immunity. J Infect Dis. 2008; 197:737-43.

104. Kristiansen PA, Diomandé F, Ba AK, et al. Impact of the serogroup A meningococcal conjugate vaccine,
MenAfriVac, on carriage and herd immunity. Clin Infect Dis. 2013;56:354-63.

105. Ramsay ME, Andrews NJ, Trotter CL, Kaczmarski EB, Miller E. Herd immunity from meningococcal serogroup C conjugate vaccination in England: database analysis. BMJ. 2003;326:365-6.

106. Daugla DM, Gami JP, Gamougam K, et al. Effect of a serogroup A meningococcal conjugate vaccine (PsATT) on serogroup A meningococcal meningitis and carriage in Chad: a community study [corrected]. Lancet. 2014;383:40-7.

107. Im JH, Woo H, Ha BM, Lee JS, Chung MH, Jung J. Effectiveness of a single dose of the quadrivalent meningococcal conjugate vaccine, MenACWYCRM, in the Korean Armed Forces. Vaccine. 2020;38:730-2.

\section{Publisher's Note}

Springer Nature remains neutral with regard to jurisdictional claims in published maps and institutional affiliations. 